\section{Visões da modernidade: análise de algumas representações artísticas sobre as transformações de São Paulo no início do século XX}

\section{Sabrina Studart Fontenele Costa}

Arquiteta e urbanista, doutoranda pelo Programa de PósGraduação da Faculdade de Arquitetura e Urbanismo da Universidade de São Paulo (FAU-USP), Rua Bagé, n.139, ap.152, Vila Mariana, CEP 04012-140, São Paulo, SP, (11) 5083-4498 e (11) 9631-3630, fontenel@usp.br

\begin{abstract}
Resumo
Este artigo pretende explicitar como as diversas transformações por que passou a cidade de São Paulo no início do século XX, relacionadas ao contexto de modificações técnicas, sociais e culturais da modernidade, fizeram-se presentes em inúmeras representações artísticas. Foram utilizados como fonte de estudo relatos de visitantes e obras em suportes variados, tais como pinturas e gravuras, textos literários (crônicas, romances e poesias) e cenas do filme "São Paulo, Sinfonia da Metrópole".
\end{abstract}

Palavras-chave: arte moderna, modernidade, São Paulo.

estudo das transformações da cidade deve ir além da análise de seus espaços físicos a partir de dados materiais - mapas, fotografias, plantas - e tenta apreender as impressões criadas em sua população. Relatos de visitantes, estudos de representações artísticas da época como pinturas e gravuras, além de textos como crônicas, romances e poesias são ferramentas para uma análise da realidade.

Este trabalho pretende apresentar um breve histórico das transformações por que passou a cidade de São Paulo na primeira metade do século $\mathrm{XX}$ a partir de alguns registros ilustrativos do período. Assim, foram utilizadas diversas fontes: o belo estudo de Nicolau Sevcenko sobre São Paulo da década de 1920, o livro de Ernani Bruno com relato de visitantes que passaram na cidade, poesias conhecidas de expoentes modernos que registraram um pouco de suas impressões sobre os novos lugares e hábitos da cidade, duas imagens de Tarsila do Amaral e cenas da cidade registradas no filme "Sinfonia da Metrópole" e nas fotografias de Benedito Junqueira Duarte.
O artigo buscou demonstrar que alguns símbolos dessas transformações da cidade - o arranha-céu, as grandes avenidas, as multidões, entre outros - foram colocados em evidência em diversas manifestações artísticas do período.

\section{São Paulo cresce e aparece}

A cidade nasceu em um plateau triangular natural em cujos vértices se instalaram, em diferentes épocas, edifícios religiosos - Mosteiro de São Bento, Convento do Carmo e Convento de São Francisco - e permaneceu durante muitos anos com as principais funções urbanas realizadas neste polígono.

Porém, ainda na gestão de João Teodoro, entre 1872 e 1875, várias melhorias foram realizadas fora do núcleo original de maneira a potencializar ocupações neste espaço: a reforma do Jardim da Luz, a regularização do largo dos Curros (hoje Praça da República), a abertura da rua João Teodoro (nos terrenos do Recolhimento da Luz) e os melhoramentos na rua do Gasômetro (SEGAWA, 2004). 
Esse crescimento vai lentamente se acentuando, de maneira que, "com a proclamação da República, em 1889, São Paulo consolida suas funções bancária, comercial e industrial e, consequentemente, vê acelerado seu processo de formação territorial com a implantação de novos loteamentos como o da Avenida Paulista, ainda no final do século XIX" (SOUZA, 2004: p.528).

A cidade se transformava de maneira cada vez mais intensa. Ainda no começo do século a antiga Catedral foi demolida e a Praça da Sé ampliada (1912), as obras do Teatro Municipal foram executadas (1903-1911) e algumas ruas do Triângulo Histórico receberam nova pavimentação e iluminação, enquanto o Anhangabaú foi remodelado.

No final da década de 1920, a proposta de criação de um grande anel de circulação que permitisse maior facilidade de deslocamento foi apresentada pelo engenheiro Prestes Maia. Intitulada "Plano de Avenidas" propunha a abertura de novas e o alargamento de antigas avenidas. Sua publicação apresentava além dos diagramas de fluxo e deslocamento, aquarelas de novos espaços conjuntos arquitetônicos, pontes, praças - que se relacionariam diretamente com as grandes avenidas e dariam um aspecto mais moderno a São Paulo. Prestes Maia acreditava que qualquer decisão de vulto para uma intervenção mais séria na cidade deveria ser tomada naquele momento.

"Estamos sob todos os pontos de vista, em um momento decisivo da nossa existência urbana. No centro os arranha-céus se multiplicam; no taboleiro alem do Anhangabahú os primeiros grandes prédios começam a emergir no meio do casario térreo; a Light prevê a renovação do contracto e intenta importantes transformações; a São Paulo Railway vê igualmente o termo de sua concessão. A várzea do Tieté, que por si só será uma cidade nova, acha-se em vias de completa metamorphose. Outras grandes obras se executam: calçamento, exgotto, abastecimento, grandes parques e edifícios públicos. A situação geral do Estado é promissora. (...) A época é, assim, muito própria para o início dos melhoramentos" (MAIA, 1929, p.07).

A partir da década de 1920, a presença do automóvel era marcante na cidade. Com a incorporação do sistema de táxis urbanos, seu volume cresceu e passava a disputar cada vez mais os estreitos espaços da área central com os bondes e pedestres.

O Plano de Avenidas foi efetivamente executado a partir de 1938 quando Prestes Maia assumiu a Prefeitura de São Paulo. Sua proposta era dar mais agilidade à cidade acentuando seu caráter rodoviarista. Neste momento, a cidade aparentava ser um grande canteiro de obras, com a demolição de antigos casarões para o alargamento e abertura de diversas vias.

Esse cenário de (re)construção de espaços consolidados parecia ser a tônica desta primeira metade do século XX. Exemplo disso foi o alargamento da Avenida São Luiz, tradicional pelos casarões de ilustres famílias de cafeicultores, que de pacata rua transformou-se em arborizada avenida que alojaria diversos arranha-céus paulistanos. Tal era a rapidez com que se erguiam novas paisagens que Claude Lévi-Strauss exclamava em 1935 "a cidade desenvolve-se com tal rapidez que é impossível encontrar-lhe um mapa: cada semana exigiria uma nova edição" (LÉVI-STRAUSS, 1981, p.190).

O passado mostrava-se como um objeto deslocado neste contexto onde nos terrenos de casas coloniais erguiam-se novas construções. Mesmo edifícios coloniais de caráter histórico como o Convento do Carmo eram destruídos como maneira natural de se alcançar o progresso. Em 1945, Prestes Maia descrevia as obras de Melhoramentos Urbanos para execução do Perímetro de Irradiação: "Praça do Carmo. A sua abertura exigiu o arrazamento de três quarteirões característicos da cidade antiga, porem sem especial interesse histórico ou artístico. Medindo 230x130 ms, é uma das maiores do centro, destinase a aliviar a Praça da Sé e proporcionar retorno aos veículos coletivos do Brás" (MAIA, 1945, s.p).

Bondes, ônibus e automóveis particulares faziam a ligação do Centro com áreas mais afastadas e recentemente ocupadas da cidade, deslocando assim freqüentemente uma massa de operários, comerciantes, executivos e profissionais liberais. Os imigrantes levavam novos sons pelas ruas através das diversas línguas que se misturavam ao português e um comportamento diferente. Novos cenários públicos, novas máquinas de deslocamento e novos hábitos: tudo parecia contribuir para um clima de fé no presente e 
no futuro. Sevcenko analisa de maneira muito interessante o clima da época:

"Por trás dessa vertigem coletiva da ação e da velocidade, engendrando-a, estimulando-a, sem permitir a reflexão sobre suas conseqüências nas mentes e na cultura, as inovações tecnológicas invadiam o cotidiano num surto inédito, multiplicandose mais rapidamente do que as pessoas pudessem se adaptar a elas e corroendo os últimos resquícios de um mundo estável e um curso de vida que as novas gerações pudessem modelar pelas antigas" (SEVCENKO, 2003, p. 162).

A sensação de estar deslocado do ambiente que se encontrava habitualmente relaciona-se com a perda da identidade histórica e a vinculação a novas imagens. Esta parece ser a descrição mais próxima do sentido da expressão modernidade apresentado por Berman (2007) quando afirma que as pessoas tentam apreender o mundo, fazer parte dele, mesmo diante de um turbilhão de novidades, ou mesmo quando o autor lança uma definição mais clara para seus sentimentos: "ser moderno é encontrar-se em um ambiente que promete aventura, poder, alegria, crescimento, autotransformação e transformação das coisas em redor - mas ao mesmo tempo ameaça destruir tudo o que temos, tudo o que sabemos, tudo o que somos" (BERMAN, 2007, p.24).

E Sevcenko destaca esse sentimento de novidade a todo momento.

"De tal modo o estranhamento se impunha e era difuso, que envolvia a própria identidade da cidade. Afinal, São Paulo não era uma cidade nem de negros, nem de brancos e nem de mestiços; nem de estrangeiros e nem de brasileiros; nem americana, nem européia, nem nativa; nem era industrial, apesar do volume crescente das fábricas, nem entreposto agrícola, apesar da importância crucial do café; não era tropical, nem subtropical; não era ainda moderna, mas não tinha mais passado. Essa cidade brotou súbita e inexplicavelmente, como um colossal cogumelo depois da chuva, era um enigma para seus próprios habitantes, perplexos tentando entendê-la" (SEVCENKO, 2003, p.31).

Neste contexto, um novo do modo de vida (ethos) instaurava-se de maneira profunda no cotidiano dos habitantes da cidade. Mas estes novos hábitos ou novas maneiras de viver não eram acessíveis a toda massa de citadinos que habitavam a metrópole, mas influenciava um número cada vez maior de pessoas. Se nem todos os cidadãos podiam comprar eletrodomésticos que facilitassem a vida no lar ou freqüentar os cinemas por questões econômicas, quase todos eram impactados pelo ritmo de vida que se fazia cada vez mais ágil pela presença de transportes de massa mais rápidos e eficientes, elevadores que deslocavam trabalhadores para alturas cada vez mais elevadas, ou até mesmo pelas novas vias e rodovias que ligavam de maneira mais eficiente as cidades brasileiras. As inovações impactavam a todos.

O filme "São Paulo, a Sinfonia da Metrópole", produzido em 1929, apresenta algumas imagens do cotidiano de São Paulo em um período de 24 horas. Eram exibidas cenas de crianças nas escolas, operários trabalhando nas fábricas, a passagem constante de carros, bondes e carroças. A cidade que se tornava industrial era exibida como numa seqüência de ordem e ritmo de eventos de maneira a enfatizar a organização, limpeza, controle e cuidados. Mas ao contrário das imagens do filme, o cenário deste momento era de uma miscelânea de eventos ocorrendo simultaneamente, numa ânsia de gerar transformações, na cidade que enriquecia e construía novos espaços originados destas riquezas.

É necessário observar as impressões do geógrafo francês Paul Walle, em 1920, quando afirmava sobre as diversas atividades da cidade neste momento:

"Diz-se que apesar de suas belas avenidas, seus monumentos, seus jardins, São Paulo era uma cidade triste e sem distrações; que quando soavam as 6 horas e o mundo dos negócios se encerrava, uma pesada solidão se abatia sobre as ruas comerciais e o silêncio se tornava tão profundo que a cidade aparecia abandonada. Essa opinião parece motivada pela calma que geralmente reina nos arrabaldes distantese nos bairros de residências particulares, principalmente no verão, quando cada um, graças às facilidades de transporte, volta rapidamente para o conforto de seu lar. É uma afirmação todavia exagerada no que concerne às ruas centrais da cidade antiga que, mais cosmopolitas, permanecem bastantes animadas até a uma hora relativamente adiantada. Os bondes passam carregados de passageiros, e os cinemas, muito numerosos, regurgitam do público, mesmo 
nos arrabaldes" (WALLE, 1981, p.184-185).

Este clima de euforia e de agitação urbano foi descrito por Sevcenko (2003) quando tratou de São Paulo dos anos 1920. O autor relata que o carnaval do primeiro ano daquela década foi marcado por grande comoção e euforia, como numa tentativa de recuperar alguns anos de restrições, sendo estas ocasionadas pela gripe espanhola que assolou a cidade e as condições climáticas que trouxeram problemas à produção de café e a saúde da população. Diversas eram as transformações ocorridas na cidade possibilitadas pelos novos hábitos - entre eles, a prática regular de esportes, a presença feminina cada vez mais constante na vida social, os freqüentes eventos culturais - que se consolidavam na cidade.

\section{Análise a partir de algumas representações artísticas}

A agitação urbana parecia encantar os poetas do período que tentam refletir em sua poesia o ritmo das mudanças, como expunha o famoso poeta cubista Blaise Cendras:

"Saint Paul

J'adore cette ville

Saint Paul est selon mon coeur

Ici nulle tradition

Aucun préjugé

Ni ancient ni moderne

Seuls comptent cet appétit furieux cette confiance absolue cet optimisme cette audace ce travail ce labeur cette speculation qui font construire dix maisons par heure de tous styles ridicules grotesque

1 Eu adoro esta cidade/ São Paulo é como meu coração/ Aqui nenhuma tradição/ Nenhum preconceito/ Nem antigo nem moderno/ Só contam esse apetite furioso essa confiança absoluta esse otimismo essa audácia esse trabalho esse esforço essa especulação que faz construir dez casas por hora de todos os estilos ridículos grotescos belos grandes pequenos norte sul egípcio yankee cubista/ Sem outra preocupação que a de seguir as estatísticas prever o futuro conforto a utilidade a mais-valia e atrair uma enorme imigração/ todos os países/ todos os povos/ eu amo isso (tradução livre da autora) beaux grands petits nord sud egyptien yankee cubiste

Sans autre préocupation que de suivre les statistiques prévoir l'avenir le confort l'utilité la plus value et d'attirer uns grossse immigration

Tous les pays

Tous les peuples

J'aime ça ${ }^{1 " \prime}$

Cendrars registra as impressões que a metrópole the causava em 1926, ocasião de sua segunda viagem. Lugar que ele ama por evocar sentimentos confusos, mas semelhantes aos seus. Não tem preconceitos, nem preferências com as pessoas. Apresenta uma vontade de crescer e de se transformar como se este fosse o único caminho a ser percorrido em busca do progresso. Por isto, constrói sem parar, sem estabelecer critérios, tanto o autor como a cidade amada.

Neste sentido, estavam em evidência três representações da expressão "modernidade" na cidade de São Paulo: os arranha-céus, as grandes avenidas e a multidão. Presentes inclusive na poesia moderna de Oswald de Andrade.

\section{"A felicidade anda a pé \\ Na Praça Antônio Prado \\ São 10 horas azuis}

O café vai alto como a manhã de arranha-céus Cigarros Tietê

Automóveis

A cidade sem mitos"

(Oswald de Andrade, Pau-Brasil).

O poema de Oswald de Andrade representa bem a atmosfera desta cidade moderna: a multidão que se espalha em um dos principais espaços públicos; o preço do café, principal produto exportador do período, que subia e estimulava uma certa euforia; os arranha-céus e os automóveis cada vez mais numerosos rodando pela cidade. Além disto, dois produtos estimulantes vinculados a hábitos modernos: o café e os cigarros.

Os símbolos desta cidade moderna entram cada vez mais em evidência a partir da década de 1920 O próprio termo "moderno" ganha ênfase como a demonstração do novo, do progresso, de liberdade, de emancipação.

"O vocábulo 'moderno' vai condensando assim conotações que se sobrepõem em camadas sucessivas e cumulativas, as quais the dão uma força expressiva ímpar, muito intensificada por esses três amplos contextos: a revolução tecnológica, a passagem do século e o pós-guerra" (SEVCENKO, 2003, p.228)

Neste sentido, o termo "moderno" era utilizado em crônicas de jornais, anúncios e letreiros espalhados pelas diversas mídias, divulgando de atividades esportivas a avanços médicos. Tudo deveria ser moderno para ser bem classificado

Duas pinturas específicas de Tarsila do Amaral ilustram um pouco da visão da autora sobre a 
Figura 1: São Paulo (135831) de Tarsila do Amaral (1924) Fonte: AMARAL, 2003, p.IV.

Figura 2: São Paulo (Gazo) de Tarsila do Amaral (1924). Fonte: AMARAL, 2003, p167 metrópole: "São Paulo (135831)" e "São Paulo (Gazo)", ambos de 1924. O primeiro quadro utiliza diversos signos da metrópole neste momento: o viaduto que contribui para o deslocamento de pessoas entre as duas áreas (provavelmente a ligação entre o Centro Novo e Centro Velho sobre o Vale do Anhangabaú, mas também qualquer outro viaduto cada vez mais comum na cena da cidade), os arranha-céus ao fundo, o bonde e um edifício de habitação popular (caracterizado à esquerda por uma série de janelas aglomeradas. Além disto, a pintora representa na obra números em série numa espécie de anúncio que pode nos remeter tanto à utilização da publicidade (elemento também bastante característico da época e do consumo), quanto a uma ferramenta comum de pintores cubistas.

A pintura "São Paulo (GAZO)" nos remete a outras representações da metrópole: as chaminés das indústrias, torres e altos edifícios servem de pano de fundo a um veículo preto e um objeto vermelho que poderíamos entender como uma bomba de gasolina (gazo?), um farol de trânsito ou mesmo como uma figura humana. Estão ainda representados fios e postes típicos das redes urbanas. Utiliza-se ainda de uma palavra solta na tela (GAZO) para apresentar um dado novo à composição, uma informação que ajuda ao observador a entender (ou confundir?) sua dinâmica.
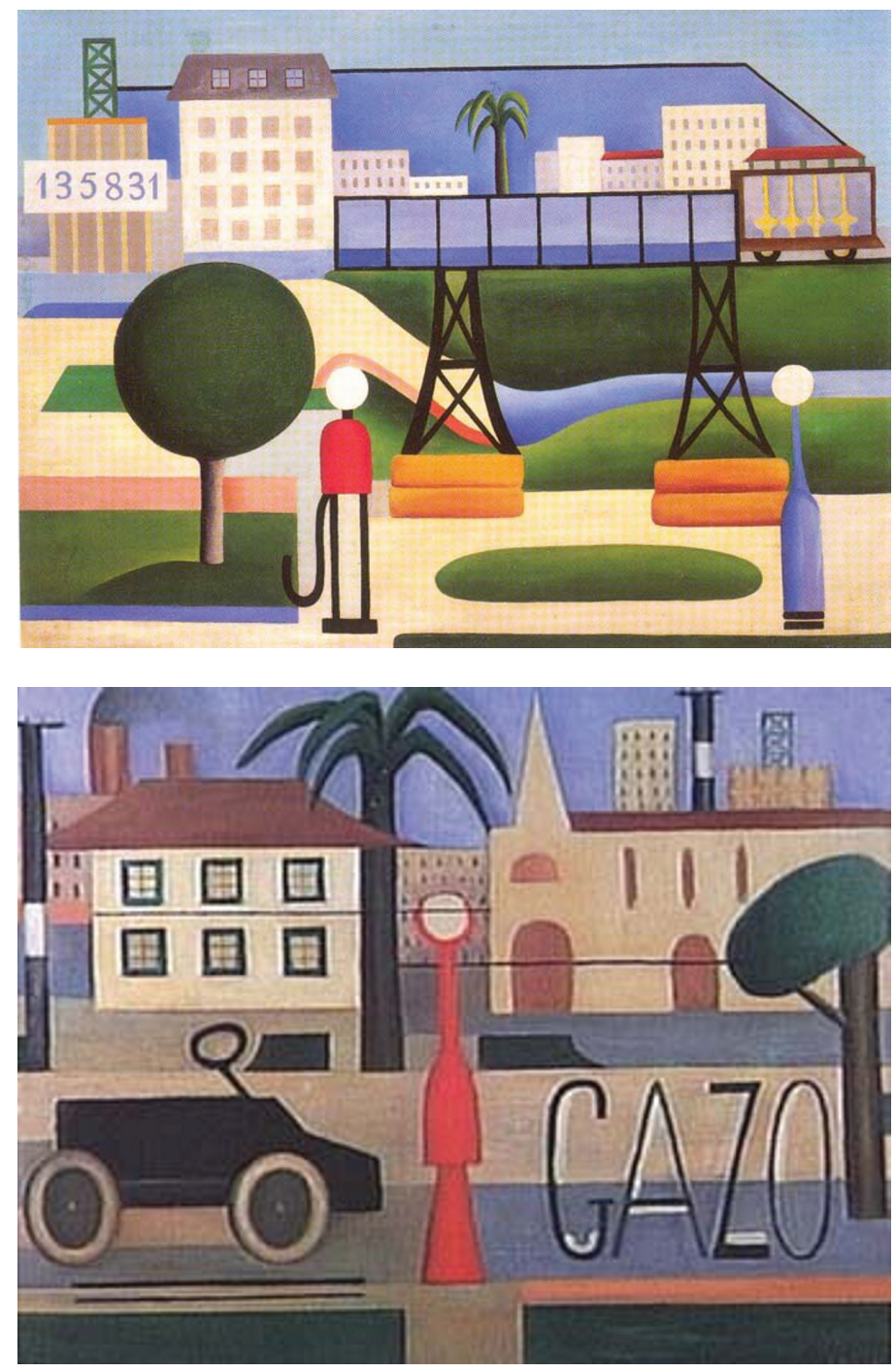
Nos dois casos analisados, Tarsila se utiliza de planos coloridos e imagens bidimensionais, de maneira a romper com as formas tradicionais de representação vinculando-se a uma linguagem moderna. Ela geometriza o objeto de maneira a lhes dar um caráter quase simbólico.

Como se pode observar, um dos elementos mais freqüentes nas obras artísticas do momento são os arranha-céus que se tornam cada vez mais comuns na cidade. O Martinelli, inaugurado em 1929, chama a atenção dos que passam pela praça Antônio Prado e marca a paisagem da cidade. A rua XV de Novembro, principal centro financeiro, vai sendo ocupada por edifícios de quatro a seis andares. Mesmo além do Vale do Anhangabaú, novos edifícios altos modificam a paisagem, entre eles o prédio da nova Biblioteca Municipal com uma torre de 23 andares.

Oswald ressalta isso na passagem sobre a Praça da Sé de Serafim Ponte-Grande:

"O Largo da Sé começou a ficar diferente por causa das Companhias Mútuas e das casas de Bombons que são umas verdadeiras roubalheiras mas que em compensação aí construíram os primeiros arranhacéus que nem chegam à metade dos últimos arranhacéus que não chegarão decerto à metade dos futuros arranha-céus" (ANDRADE, 1971, p. 141).

Os arranha-céus eram cada vez mais citados como exemplo de avanço econômico e tecnológico de São Paulo. Um bom exemplo disto seria o edifício Martinelli (1929). Localizado no cruzamento da importante avenida São João com a rua Líbero Badaró, este edifício marcou de maneira fundamental a passagem da cidade horizontal de tijolo de então para a ocupação vertical dos edifícios de concreto armado. Apresentava um desenho bastante eclético e foi construído para marcar o poder do imigrante em São Paulo e assegurar seu caráter monumental.

Durante um longo período, o desenho do Martinelli marcou o perfil do Centro de São Paulo e o imaginário de sua população que associava o arranha-céu corde-rosa a um símbolo de progresso tecnológico fruto da fase que a cidade passava. Mário de Andrade já registrava em sua crônica de 1930 a comparação do domínio dos céus entre o dirigível que passava em São Paulo naquele momento e o arranha-céu, quando exclamava: "E o Zeppelin veio provar para São Tomé o sofisma gracioso de que uma casa dum andar pode ser mais alto que o Martinelli" (ANDRADE, 1976, p.199).

Maria Cecília Naclério Homem declarava que "a capital superava os seus próprios recordes e os das demais cidades brasileiras. Em 1920, as estatísticas registraram 1.875 novas construções, que evoluíram para 3.922, em 1930. Construía-se à razão de uma casa por hora" (HOMEM, 1984, p.45). Daí surge a expressão que marcava o período: "São Paulo, a cidade que mais cresce no mundo" colocada e repetida alguns anos mais tarde, durante os festejos do IV Centenário em 1954.

As mudanças que ocorriam na cidade eram registradas pelas lentes do fotógrafo Benedito Junqueira Duarte. Convidado por Mario de Andrade, em 1937, para organizar o acervo fotográfico da Sessão de Iconografia do recém-criado Departamento de Cultura, ele foi responsável também por registrar cenas do cotidiano da metrópole, das obras de melhorias urbanas (entre elas, abertura da Avenida Nove de Julho, remodelação do Parque Anhangabaú, alargamento da Avenida Ipiranga e abertura da São Luiz, construção do estádio Municipal do Pacaembu, retificação do rio Tietê, construção das Pontes das Bandeiras e do Jaguaré) e personagens do período. Suas fotografias são um belo registro histórico e artístico dessas transformações da cidade.

Os edifícios altos eram estimulados pela própria municipalidade com leis que incentivavam uma corrida às alturas. Para se ter um exemplo, enquanto na Lei $n^{\circ} 2332$ de 1920 existia um gabarito máximo para algumas vias da área central², nove anos depois, no Código Arthur Saboya de 1929 (Lei n 3427) o mesmo tipo de rua tinha estabelecidas alturas mínimas ${ }^{3}$. Assim, era possível a qualquer visitante entender numa visita rápida ao centro que se encontrava no coração da cidade, pois "sua paisagem inconfundível, a impressionante intensidade do tráfego de veículos e de pedestres, a presença das melhores lojas, o bloco compacto de arranha-céus - tudo ocorre para defini-lo e para assegurar sua individualidade" (MULLER, 1958, p.121).

Assim, era comum a presença de uma massa de pessoas a se deslocar pelas ruas, estimulando o uso cada vez mais constante do termo "multidão" nos 
relatos do período. Um grande número de pessoas reunidas em algum espaço público, como na Praça Antônio Prado, coração da cidade naquele momento; ou inúmeros transeuntes tentando cruzar avenidas repletas de carros são registradas em fotografias da época.

Na região do Centro Novo, durante o dia, atividades como serviço e comércio atraíam um grande número de usuários, e, pela noite, os cinemas e teatros da região recebiam as pessoas em busca de lazer. Grande parte das atividades culturais que se desenvolviam - de maneira cada vez mais comum - na cidade implantavam-se em edifícios do Centro Novo.

No entorno da avenida São João, era visível a concentração de cinemas. Essa forma de entretenimento inseria-se de maneira cada vez mais forte no cotidiano das diversas classes sociais. Nesta região, até o final da década de 1940, já estavam implantados os cines Bijou-Palace (1907), Central (1916), Avenida (1919), Broadway (1935), Art Palácio (1936), Metro (1938), Ipiranga (1943), Ritz (1943), Marabá (1945), e nas décadas seguintes, mais salas de cinema seriam construídas na região. Por este motivo, era conhecida como Cinelândia. Os espaços eram projetados para receber um público significativo, tendo algumas salas capacidades para 1.450 espectadores (SANTORO, 2004). A multidão tomava as ruas antes e depois das principais sessões de filmes. Assim, como nas disputas de futebol cada vez mais constantes na cidade.

Curioso ainda observar que a região da Cinelândia funcionava de dia como espaço do trabalho, dos escritórios, do comércio, enquanto a noite era um centro de lazer, ao mesmo tempo ladeado por edifícios de habitação cujo programa integrava-se a essa mistura de usos e de tempos, além de promover uma integração de tipos e de grupos.

No início do século, o francês Pierre Denis dizia que, no Brasil, apenas em São Paulo e Rio de Janeiro pode-se ver uma multidão (DENIS, 1981, p. 144). Não era para menos. A população crescia rapidamente e tomava as ruas, com o passo apressado, em busca de trabalho e diversão, disputando espaço com os veículos nas ruas.

\section{Considerações finais}

As representações artísticas e culturais encontram na cidade infinitas possibilidades de manifestações. O espaço urbano e seus agentes, em constantes transformações, têm seus momentos flagrados pela arte e a cultura se constrói a partir dessa interação contínua.

Esse trabalho buscou, portanto, refletir sobre algumas representações da cidade de São Paulo, ilustrativas de inúmeras transformações pelas quais passou a metrópole nas primeiras décadas do século $X X$. Considerou que a arte moderna neste período tentava compreender o sentido da palavra modernidade por meio de algumas representações que ressaltavam a escala macro que a cidade tomava: os altos edifícios, as novas avenidas e a grande quantidade de pessoas que se deslocavam pela cidade. São Paulo crescia, novos cenários urbanos eram construídos e novos referenciais eram criados. Estes elementos eram dados que refletiam na produção artística dos homens que viviam ou visitavam a cidade que "mais cresce no mundo".

\section{Referências bibliográficas}

AMARAL, Aracy. Blaise Cendrars no Brasil e os modernistas. São Paulo, Editora 34, 1997.

A imagem da cidade moderna: o cenário e seu avesso. In: FABRIS, A. (org.). Modernidade e Modernismo no Brasil. Campinas, Mercado das Letras, 1994.

ANDRADE, Mario de. Táxi e crônicas no Diário Nacional. São Paulo, Duas Cidades, Secretaria de Cultura, Ciência e Tecnologia, 1976.

ANDRADE, Oswald. Memórias sentimentais de João Miramar. Serafim Ponte Grande. Rio de Janeiro, Civilização Brasileira, 1971.

BERMAN, Marshall. Tudo que é sólido desmancha no ar. São Paulo, Companhia das Letras, 2007.

CAMPOS, Candido Malta. Os rumos da Cidade: Urbanismo e modernização em São Paulo. São Paulo, Senac, 1999.

DENIS, Pierre. É acima de tudo uma grande cidade de negócio. In: BRUNO (org.). Depoimentos de Moradores e visitantes. 1553-1958. São Paulo, Prefeitura do Município de São Paulo, Secretaria Municipal de Cultura, Departamento de Patrimônio Histórico, 1981.

HOMEM, Maria Cecilia Naclerio. O prédio Martinelli. A ascensão do imigrante e a verticalização de São Paulo. São Paulo, Projeto Editores, 1984. 
LEVI-STRAUSS, Claude. Cidade selvagem, como o são todas as cidades americanas. In: BRUNO (org.). Depoimentos de Moradores e visitantes. 1553-1958. São Paulo, Prefeitura do Município de São Paulo, Secretaria Municipal de Cultura, Departamento de Patrimônio Histórico, 1981.

MAIA, Francisco Prestes. Estudo de um Plano de Avenidas para a cidade de São Paulo. São Paulo, Companhia de Melhoramentos de São Paulo, 1929.

Os Melhoramentos de São Paulo. São Paulo, Prefeitura Municipal, 1945.

MULLER, Nice L. A área central da cidade. In: AZEVEDO (org.). A cidade de São Paulo: estudos de geografia urbana. São Paulo, Companhia Editora Nacional, 1958.

PORTA, Paula. História da Cidade de São Paulo. São Paulo, Paz e Terra, 2004

QUEIROZ, Suely Robles Reis. Política e poder público na Cidade de São Paulo: 1889-1954. In: PORTA (Org.). História da cidade de São Paulo. A cidade na primeira metade do século XX. São Paulo, Editora Paz e Terra, 2004

SANTORO, Paula. A relação da sala de cinema e o espaço urbano em São Paulo: do provinciano ao cosmopolita. São Paulo, FAU-USP, 2004.
SEGAWA, Hugo. São Paulo, veios e fluxos: 1872-1954. In: PORTA, P. (org). História da Cidade de São Paulo. São Paulo, Paz e Terra, 2004, v.03.

SEVCENKO, Nicolau. Orfeu extáltico na metrópole: São Paulo, sociedade e cultura nos frementes anos 20. São Paulo, Companhia das Letras, 2003.

SIMÕES JR, José Geraldo. Anhangabaú: história e ur banismo. São Paulo, Faculdade de Arquitetura e Urbanismo, 1995.

SOUZA, Maria Adélia Aparecida. Metrópole e paisagem: caminhos e descaminhos da urbanização. In: PORTA, P. (org). História da Cidade de São Paulo. São Paulo, Editora Paz e Terra, 2004.

TOLEDO, Benedito Lima de. São Paulo: três cidades em um século. São Paulo, Cosac Naify, Duas Cidades, 2007.

WALLE, Paul. Diz-se que São Paulo é uma cidade triste e sem distrações. In: BRUNO (org.). Depoimentos de Moradores e visitantes. 1553-1958. São Paulo, Prefeitura do Município de São Paulo, Secretaria Municipal de Cultura, Departamento de Patrimônio Histórico, 1981 
Visions of modernity: analysis of some artistic representations of transformations of Sao Paulo in the beginning of the twentieth century

Sabrina Studart Fontenele Costa

\begin{abstract}
The city of Sao Paulo changed a lot in the first decades of XX century, what induced many artistic manifestations based on this theme. This paper aims to describe how the changes in the city influenced the communication manifestations during the beginnig of XX century. Tourists impressions and artistic expressions, such as paintings, engravings, literature (chronicles, novels and poetry) and scenes of the movie "Sao Paulo, Sinfonia da Metropole", were used as object of study.
\end{abstract}

Keywords: modern art, modernity, Sao Paulo.

Visiones de la modernidad: análisis de algunas declaraciones artísticas sobre las transformaciones de Sao Paulo al principio del siglo XX

Sabrina Studart Fontenele Costa

\title{
Resumen
}

Este artículo pretende explicitar como las diversas transformaciones por las que paso la ciudad de San Pablo en el inicio del siglo XX, relacionadas al contexto de modificaciones técnicas, sociales y culturales de la modernidad, se hicieron presentes en inmumerables representaciones artísticas. Fueron utilizados como fuente de estudio relatos de visitantes y obras em soportes variados, tales como pinturas y dibujos, textos literários (crônicas, romances y poesias) y escenas da película "São Paulo, Sinfonia da Metrópole".

Palabras clave: arte moderno, la modernidad, Sao Paulo. 